\title{
Promoviendo la lectura en ámbitos extraescolares: un círculo para adolescentes en Coscomatepec, Veracruz, México'
}

\author{
Promoting Reading in Extracurricular School Activities: \\ A Circle for Teenagesrs in Coscomatepec, Veracruz, Mexico \\ LAURA PUC DOMÍNGUEZ
MARIO MIGUEL OJEDA RAMÍREZ \\ Universidad Veracruzana \\ México \\ laura_flpd@hotmail.com \\ mojeda@uv.mx \\ (Recibido: 24-O2-20I7; \\ aceptado: 2I-IO-2OI7)
}

Resumen. Este artículo expone un marco referencial sobre promoción de la lectura en México, justificando las acciones independientes que contribuyen al arraigo de iniciativas más allá de los ámbitos escolares e institucionales. Después de hacer una revisión de antecedentes y dar una serie de pautas teóricas y metodológicas, se reporta una intervención que consistió en un círculo de lectura con adolescentes de entre 13 y 16 años de edad, en el municipio de Coscomatepec de Bravo, en la zona centro del estado de Veracruz, México. El trabajo se realizó durante 12 sesiones en un espacio externo a la escuela. Se comenta los métodos de evaluación de la estrategia; se describe los resultados de la intervención, relacionando la encuesta diagnóstica de hábitos lectores aplicada al inicio con las evidencias de las actividades realizadas. Se trata de una experiencia satisfactoria que ya ha trascendido entre los adolescentes de este lugar.

Palabras clave: Lectura; adolescentes; intervención; promoción; actividades.
Abstract. This article presents a reference framework on promoting reading in Mexico, justifying the independent actions that may contribute to the establishment of initiatives beyond the school and institutional spheres. After reviewing the background scholarship and examining a series of theoretical and methodological guidelines, we describe an intervention that consisted of a circle of adolescents between 13 and 16 years of age, in the municipality of Coscomatepec de Bravo, in the central area of the State of Veracruz, Mexico. This circle was developed during 12 sessions in an extracurricular space. The methods of evaluating the strategy are discussed.We describe the evaluation methods of the intervention, and relate the diagnostic survey of reading habits from the beginning of the study, to the results from the activities performed. This has been a satisfactory experience that has already gained traction among the young people of this municipality.

Keywords: reading; adolescents; intervention; promotion; activities.

\footnotetext{
I Para citar este artículo: Puc Dominguez, Laura y Ojeda Ramírez, Mario Miguel (2018). Promoviendo la lectura en ámbitos extraescolares: un círculo para adolescentes en Coscomatepec, Veracruz, México". Alabe 1\%. [www.revistaalabe.com] DOI: IO.I5645/Alabe2OI8.I7.6
} 


\section{Introducción}

Entre los lugares comunes del tema de la lectura se puede encontrar aseveraciones tales como que quien tiene el hábito de leer lo hace por gusto; que la lectura correcta y constante comienza desde la infancia; que vivimos en un país donde casi nadie lee, y que quienes constituyen la excepción a la regla leen demasiado o por obligación; que en la escuela no se trabaja lo suficiente para promover la lectura y por ello los niveles de desempeño de los estudiantes son alarmantemente deficientes. En años recientes, también se ha difundido la idea de que el arribo de los dispositivos tecnológicos a la vida cotidiana ha modificado de forma notable el proceso comunicativo y, en ese sentido, la lectura silenciosa y el libro como objeto están en la cuerda floja.

Sin embargo, vale la pena cuestionar: ¿De verdad a nadie le interesa la lectura en México, inmersos como estamos en la crisis económica, política, educativa, ambiental, de seguridad, de valores e incluso de identidad? ¿Por qué no se lee o sí se lee? y ¿En qué sentido leer transforma nuestra vida, como suele decirse de forma tan poética e inexacta?

En un documental de Gómez Martínez (2OI4) se hace una serie de entrevistas a 5o lectores mexicanos que aseguran que les gusta leer. Desde su posición como estudiantes, comerciantes, promotores y animadores de lectura, amas de casa, adolescentes, niños, ancianos, artistas o profesionales de la salud, cada uno describe cómo comenzó a leer, cómo se lleva a cabo su momento de lectura, cómo ha evolucionado su experiencia académica, laboral o social y cuáles fueron los factores que condicionaron su disposición o indisposición a la lectura. ¿Los resultados? Mexicanos satisfechos por hacer de la lectura un momento especial del día o de la semana, a contracorriente de las obligaciones comunes tales como atender un negocio, la práctica de un deporte o criar a sus hijos; mexicanos que empezaron leyendo best sellers y ahora son lectores devotos de la prosa de Mario Vargas Llosa o de Octavio Paz; mexicanos que traen consigo complicadas historias de vida, que no tuvieron la oportunidad de concretar una carrera universitaria ni los estudios básicos, o que han salido adelante con capacidades diferentes, o a través de experiencias personales muy duras.

¿Cómo puede un país acabar con los prejuicios que lo destruyen si los adopta como recurso de justificación? ¿La falta de lectura justifica la ignorancia? No, siendo estrictos, la explica, pero no hay justificación para que más de 9o\% de la población que sabe leer y escribir en nuestro país funja como analfabeta funcional. Sin embargo, lo interesante de este documental es que parte de una premisa positiva: ¿por qué se lee?

Es fundamental reconocer las circunstancias que rodean el hábito lector si lo hay, y dejar de subestimar la voluntad, si no lo hay, para poder sencillamente empezar a leer. Reconocer las características del ambiente que nos agrada, analizar con qué intención accedemos a un texto y dilucidar con exactitud qué tipo de texto leemos por solaz, gozo, placer o esparcimiento, y qué otro consiste en una herramienta de trabajo o estudio. Más importante, compartir la lectura, socializarla, aprender a dar de lo que el libro nos aportó. 
¿Es esto posible? Sí. De hecho, la lectura se concibe como un fenómeno sociocultural, la que define la calidad de vida de un país, que se vuelve herramienta básica junto con la inseparable escritura en la Internet, la que da vida a discusiones críticas y reflexivas sobre el pensamiento y la existencia misma (Cassany, 2006). Fomentar la lectura socializándola, promoverla sin imponerla, discutirla y producir nuevas ideas a partir de ésta, son retos que las sociedades lectoras han llevado a cabo desde tiempos remotos. Tal parece que es ésta la visión de lectura que ha prevalecido en los programas de enseñanza, la que ha conducido a los profesores a prácticas autoritarias que exprimen a jóvenes lectores en busca de una respuesta que se parezca a la que consideramos correcta, dejando de lado el valor de la oralidad y de la escritura bien realizada.

Recientemente la Dirección General de Publicaciones del Consejo Nacional para la Cultura y las Artes (CONACULTA) dio a conocer los resultados de la Encuesta Nacional de Lectura y Escritura 2OI5-20I8, realizada con el fin de respaldar programas públicos y privados de fomento a la lectura. Se concluyó que en México se leen 5.3 libros al año (índice mayor que el de años anteriores). De 5, 845 encuestados, $59 \%$ declara que compra libros; ir.6\% descarga textos y casi el 80 \% escribe con el fin de comunicarse. Lo interesante es que las personas afirman que en su tiempo libre prefieren ver televisión, practicar deporte, reunirse, conversar, todo esto antes que leer (CONACULTA, 2OI5). Las cifras podrán elevarse pero lo importante es que no dan a la lectura un lugar preponderante entre los hábitos de los mexicanos. Estamos, entonces, inmersos en una sociedad que no favorece sustancialmente a los jóvenes para convertirse en lectores.

Este trabajo se basa en el proyecto de intervención que realizó el primer autor como parte de su proceso formativo en la Especialización en Promoción de la Lectura, un programa de posgrado de la Universidad Veracruzana, siguiendo los lineamientos establecidos por el segundo autor. La propuesta de intervención fue sometida a los diferentes ámbitos colegiados y se realizó durante el 20I5. El artículo que aquí se presenta se deriva del trabajo recepcional sometido y defendido correctamente a principios de 20I6. El artículo está integrado por seis apartados. El primero presenta una revisión del estado de la cuestión y el segundo es una nota sobre los fundamentos teóricos; después, en el tercero y cuarto, se presenta el contexto de la intervención así como los objetivos y la estrategia metodológica seguida; posteriormente se describe la intervención realizada, para dar lugar a los resultados, discusión y conclusiones. 


\section{Revisión de algunos antecedentes}

Manguel (2OII) comparte su visión de la lectura como una actividad susceptible de aplicarse a todo aquello que se conoce. Leemos todo el tiempo, no sólo decodificamos letras: todo lo que existe y se puede interpretar es una lectura. Este proceso de pensamiento nos permite comprender lo que está a nuestro alrededor. Garrido (2012: 33) explica que "en un sentido amplio, leer consiste en descifrar los mensajes que los signos guardan, reconocerlos, interpretarlos, esforzarse por comprenderlos”. Encaminados en la lectura que nos transmite conocimiento de mundo, tenemos aquella que resulta de la práctica social del lenguaje, mismo que adquirimos a partir de nuestro nacimiento, insertos en una comunidad que posee una lengua determinada.

Cassany (2006) afirma que leer es un "verbo transitivo" puesto que la actividad lectora va mucho más allá del acto de obtener información. Leer, como inminente manifestación del lenguaje, implica adentrarse, conocer y comprender una visión del mundo. A partir de aquí, Cassany plantea tres posibles abordajes de la lectura: la lingüística, que existe por sí misma en tanto que las palabras han sido escritas en papel; la psicolingüística, es decir, aquel proceso en que el lector se enfrenta con el texto, lo conoce, interpreta y se apropia al hacerlo coincidir con sus propias experiencias; y por último, la concepción sociolingüística, la cual se dimensiona a partir de que el lector es capaz de compartir lo que ha leído con los demás, creando una red de comprensión, reflexión e interpretación mayor. Entonces, son las últimas dos concepciones de lectura las que interesan para este proyecto, ya que al establecer un círculo de lectores, la interpretación individual da paso a una creación colectiva, matizada por las formas de pensar y sentir de varios lectores unidos por el mismo interés.

El concepto de lectura es interesante, pero la práctica de la misma lo es aún más. Según Jiménez las prácticas lectoras:

(...) son las condiciones, libros y necesidades de lectura con las que se lee dentro de un gran panorama de textos y espacios a su disposición. Estas prácticas incluyen, además de la alta literatura, libros bestseller, novelas románticas, circuitos de lectura infantil y académica, pero también las revistas de notas de espectáculos, folletines de poesías decimonónicas y, ampliando aún más estos circuitos: todas aquellas maneras en las que los lectores se apropian de historias (citada en Ramos, 2015: 5).

Para acceder a este concepto resulta importante reflexionar sobre la forma en que el lector se encamina al encuentro con el texto; es decir, si ha creado un hábito, el cual puede basarse tanto en la repetición de una decodificación de signos como en la adquisición de las competencias que esta actividad comprende. ¿Y de qué depende que una persona posea o no un hábito lector? De que haya tomado alguno de dos caminos posibles: el de la lectura obligatoria o el de la lectura voluntaria (DINLE, 2OI3). Es necesario conocer los motivos por los cuales un adolescente prefiere tal o cual espacio, tema, momento y hasta formato para leer, y sin duda, conocer el grado en que la lectura obligatoria ha influido en su disposición para tal fin. 
Este proyecto surgió con el propósito de que los adolescentes que han vivido en un entorno poco estimulante a la lectura, se apropiaran de ésta y a partir de ahí, construyeran su propia historia de vida; es decir, que llevaran a cabo una práctica lectora con todo lo que ésta implica. Se trabajó con la conocida dinámica de círculo de lectores porque se consideró esencial compartir y retroalimentar lo que la lectura nos aporta, convirtiéndola en un proceso sociocultural. De acuerdo con Colomer:

Compartir las obras con las demás personas es importante porque hace posible beneficiarse de la competencia de los otros para construir el sentido y obtener el placer de entender más y mejor los libros. También porque hace experimentar la literatura en su dimensión socializadora, permitiendo que uno se sienta parte de una comunidad de lectores con referentes y complicidades mutuas (2005: 194).

Los adolescentes se encuentran en un momento de transición vital en el que el duelo por la pérdida de la infancia y la imposibilidad de alcanzar la adultez inmediata provocan crisis, aislamiento o rebeldía. Poner a su alcance una vía de construcción de identidad propia no sólo los ayudaría a sentirse acompañados y comprendidos, sino a crear nuevas formas de expresión a partir de los textos. Tal como definen Chance y Lesesne (2OI2), las pláticas sobre lectura o booktalks son la oportunidad sencilla y perfecta de atraer lectores a través de recomendaciones entusiastas y coincidencia de intereses al interior de un grupo.

Pero ¿cómo refrescar la actividad de un círculo de lectores en pleno siglo XXI? Actualizando los recursos de producción y expresión de ideas. Los jóvenes del grupo concreto con quienes se aplicó la intervención, si bien habitan una región no totalmente urbanizada, tienen acceso a recursos tales como computadoras, internet, información y dispositivos móviles como tabletas o teléfonos inteligentes. Una manera de hacer interesante la lectura para ellos es dándole un sentido de unidad con lo que ellos tienen que decir, y si eso que desean expresar se hace público; hay suficientes razones para interesarse aún más por lo que otros (los autores) han dicho. La difusión de las actividades y producciones escritas en contextos digitales posibilita esas nuevas dinámicas de interacción.

Otro término fundamental para este trabajo es el de promoción de la lectura, ya que la finalidad de intervenir en el grupo concreto es que los integrantes se acerquen al mundo de la lectura gracias a la labor promotora. Se trata entonces de una labor social, un contacto con la comunidad mediante un acto mental que implica conocimiento, libertad, voluntad y trabajo constante. En palabras de Morales:

La promoción de la lectura es una práctica social dirigida a transformar positivamente las maneras de percibir, sentir, valorar, imaginar, usar, compartir y concebir la lectura como construcción sociocultural. Desde esta perspectiva, la promoción de la lectura relaciona al hombre con la lectura. Ésta no siempre es consciente e intencionada, pero sí voluntaria, comprometida, militante y de convicción (2005: 2OI). 
Se debe reconocer que la promoción de la lectura constituye un amplio camino para orientar el hábito lector, fortalecer las prácticas y aprovechar los recursos comunicativos más allá de las aulas, sin distinción de edad, género o nivel sociocultural, en ambientes apropiados, mediante selecciones de textos bien dirigidas e intencionadas.

Bahloul (I998) describe en qué consiste la diferencia entre lectores y no lectores; en un estudio sociológico realizado en Francia, donde se propone que en vez de basarse en resultados cuantitativos arrojados por encuestas, generalmente catastróficos y generadores de lugares comunes como las frases "en este país nadie lee", "los jóvenes ya no se acercan a la lectura", entre varias otras, surge la posibilidad de hacer un estudio cualitativo, que permita la comprensión de los procesos lectores. Bahloul realizó encuestas cuidadosamente diseñadas a fin de acercarse a los lectores, reconstruir su entorno, conocer qué le motiva, qué estudió, cuáles fueron los orígenes de su interés o desinterés por la lectura, qué estudiaron sus padres, qué lo llevó a practicar la profesión y el oficio que ahora tiene, cómo lee, cuándo lee, por qué lee.

Otra aproximación a la manera en que los jóvenes dan sentido a sus prácticas lectoras, pero en un contexto hasta cierto punto similar al de la sociedad mexicana, es el estudio socioetnográfico realizado por Storni (2009) en Argentina, específicamente en la región de los Andes. Mediante una serie de entrevistas a jóvenes tucumanos, se muestra que la lectura contribuye a la construcción de nuevas relaciones sociales y constituye una práctica cuyo significado depende de quienes la llevan a cabo.

Las nuevas formas de sociabilidad tienen lugar porque la lectura se articula con las otras acciones que un individuo lleva a cabo en su vida cotidiana, pero también porque en esta articulación no quedan fuera todos los sistemas y formas de comunicación que los rodean y forman parte del entorno mediático. El análisis de los casos citados da cuenta de formas de utilización de los medios de comunicación y las nuevas tecnologías que potencian las prácticas de lectura, las acompañan y las profundizan contradiciendo la idea de la responsabilidad de los mismos en la falta de lectura (Storni, 2009: I2).

Entre las conclusiones de este estudio, cabe señalar que los medios de comunicación masiva destacan no como distractores de la lectura sino como amplias vías de interacción entre los jóvenes para el intercambio de ideas, textos y puntos de vista surgidos de la lectura. Entonces, la posibilidad de fomentar la producción multimedia a partir de la lectura se constituye como una propuesta viable.

Ya que la dinámica esencial de esta intervención fue el círculo de lectura, es necesario abordarlo tanto al interior de la escuela como fuera de ella. Como se mencionó anteriormente, Chance y Lesesne (2OI2) dan a conocer un retorno a la estrategia básica, las pláticas sobre libros en las que los jóvenes se sientan motivados con el entusiasmo lector de otras personas. Tradicionalmente, las booktalks consisten en poner al alcance del lector potencial un libro que le interese, leer más sobre el mismo tema, género o autor y a partir de ahí, recrear una escena, identificar las características de los personajes, pro- 
yectar imágenes e ideas relacionadas con la lectura, armar nuevas historias con el vocabulario derivado de la misma, entre otras varias. Esta disertación, implicada en el ambiente de la escuela secundaria, destaca los beneficios de los círculos de lectura ya conocidos: ayudan a encontrar libros y a disfrutarlos, elevando su entusiasmo, la interacción con los adultos, aprenden del disfrute de los compañeros, etc. (Chance y Lesesne, 2OI2).

Gracias a estas propuestas de construcción e interacción, el fundamento metodológico del círculo de lectura adquiere su justa dimensión y lugar. En un estudio sobre la conversación literaria en las aulas de clase, Chambers (2002) expresa que el hecho de hablar de literatura al interior de un grupo constituye un "acto de contemplación", ya que los pensamientos y emociones van adquiriendo forma cuando entre varias personas se interpreta la lectura. Poco a poco, la palabra hablada y escrita nos hace responsables de nosotros mismos y nos conduce por la ruta del discernimiento, la opinión y la proposición, a través de mapas en cuyos cruces, inevitable y afortunadamente, encontramos la mirada del otro. La lectura sirve para establecer vínculos sociales, nos induce a desarrollar tanto el sentido de identidad como el de pertenencia, nos impulsa a salir de nuestra introspección para comprobar aquello que hemos conocido en las páginas. Petit expresa claramente la función social de la lectura:

Leer, como lo hemos visto, es tener un encuentro con la experiencia de hombres y mujeres, de aquí o de otras partes, de nuestra época o de tiempos pasados, transcrita en palabras que pueden enseñarnos mucho sobre nosotros mismos que no habíamos explorado o que no habíamos sabido expresar. Conforme pasan las páginas sentimos surgir en nosotros a un tiempo la propia verdad, más subjetiva, más íntima, y la humanidad compartida. Y esos textos que alguien nos pasa y que nosotros pasamos a la vez, representan la apertura hacia círculos de pertenencia más amplios, más allá del parentesco, de la localidad, de la etnicidad (2003: 98).

La lectura se convierte así en un círculo concéntrico donde el individuo, creador de ideas, miembro de un grupo, se encuentra en un proceso de constante cambio e intercambio, vive crecimiento individual como sujeto cognoscente y aporta a los demás una visión propia del mundo para generar ideas universales.

Un caso basado en la interacción lectora que se ubica en América Latina y remarca la importancia de la recomendación entre los jóvenes, es el descrito por Castronovo (2004), donde explica cómo se propuso la idea de hacer una feria del libro dentro de una escuela secundaria de Buenos Aires, evento en el que participaron todos los profesores, no sólo los encargados de la materia de lenguaje. Los jóvenes de entre i2 y i8 años, colaboraron de manera entusiasta en la planeación y materialización de este proyecto, después de haber estado en contacto con la lectura bajo un programa sistemático. Lo que parecía un proyecto rústico y poco probable, se convirtió no en una experiencia masiva, pero sí en una actividad constante que integró a la comunidad bajo la premisa de que leer es importante, es necesario y es bueno. Este caso destaca la interacción del lector con su entorno y convierte al adolescente en difusor de su propia identidad a través de la lectura, 
cuestión que, para los fines del presente proyecto de intervención, vale la pena atender sobre todo en un medio donde el contacto con actividades culturales es verdaderamente limitado.

\section{Una nota sobre fundamentos teóricos}

El proyecto encuentra su base teórica en dos corrientes surgidas a lo largo del siglo XX, las cuales, desde diferentes áreas de estudio, dirigen sus postulados hacia la creación de sentido y significado. Éstas son el constructivismo y el interaccionismo simbólico; la primera, como corriente pedagógica, plantea la posibilidad de que el ser humano construya -como su nombre lo indica- su propio conocimiento, enfrentando problemas que deberá resolver con la ayuda de herramientas proporcionadas por facilitadores, quienes habrán de observar cómo las ideas del sujeto se modifican y se vuelve capaz de proseguir con su aprendizaje, de forma dinámica y crítica. Según Jean Piaget, el sujeto se relaciona con el entorno para producir el conocimiento mediante procesos mentales individuales, aprovechando los conocimientos previos para generar nuevas ideas. Piaget se enfoca en estudiar las estructuras lógicas de pensamiento que conducen a una mayor y mejor adquisición de conocimiento, de manera exclusivamente interna, sin determinar la manera en que influye el factor social. Desde el punto de vista de Gómez y Coll (I994, p. 4): "las propuestas pedagógicas inspiradas por el constructivismo piagetiano se caracterizan fundamentalmente por la poca atención prestada a los contenidos y a la interacción social (y, como consecuencia, a la instrucción)".

En el punto en que el constructivismo alcanza a contener todo aquello que produce el individuo, entra el interaccionismo simbólico para apoyar en la explicación de cómo la lectura representa una vía de tránsito de significado y generación de sentido. Esta corriente microsociológica tiene su fundamento en la antropología y la psicología social. Propone que la sociedad sea susceptible de conocimiento gracias al acto comunicativo. Desde un punto de vista coincidente con el constructivismo, aquí el ser humano tampoco es un receptor pasivo de conocimiento, sino un ente con la capacidad de crear símbolos a partir de objetos e ideas que provienen de su entorno y que, una vez aprendidos, los "re-significa" gracias al intercambio con otros miembros de la sociedad. De esta forma se crea una red de interacciones donde el intercambio es la clave de acceso al conocimiento y creación de nuevas ideas. Desarrollado previamente por Dewey y Mead, es con Herbert Blumer (Pons, 2OIO) con quien esta corriente recibe su nombre y se define bajo determinadas premisas. Cuando el ser humano interactúa con su entorno, cada objeto se convierte dentro de él en un símbolo -es decir, lo que es capaz de comprender, lo que simboliza- y con base en este conocimiento de mundo, intercambia ideas con los demás, complementando sus saberes y dando paso a otros ámbitos más allá de los sentidos, donde se encuentran el razonamiento y la imaginación. 
El interaccionismo simbólico busca significados en la interacción de los individuos y los grupos, en los símbolos utilizados y en cómo los cambios de símbolos cambian el comportamiento de las personas. Sus métodos de investigación preferentes son cualitativos, extrayendo el significado de símbolos, contenidos y palabras: análisis de contenido, categorizando respuestas; observación participante en los mismos escenarios en que acontecen las interacciones de la vida social; entrevistas, grupos de discusión o análisis documentales, son algunos de los métodos de investigación utilizados (Pons, 20IO: 30).

Gracias a la interacción social las personas aprenden los significados y símbolos, poniendo en juego la capacidad distintivamente humana de pensamiento. Al entrar en contacto con los demás, los símbolos se transforman, crecen, se nutren de la interpretación de los otros modificándose de tal manera que lo aprendido se vuelve un constructo individual -debido a la capacidad del ser humano de comunicarse consigo mismo- pero también social, dando lugar a pautas que habrán de constituir grupos y sociedades.

Dentro de esta propuesta de intervención, el interaccionismo simbólico brinda un enfoque consecuente al constructivismo, ya que al recibir la influencia de la promoción de la lectura, una persona puede construir su propio conocimiento leyendo textos: decodifica, analiza, sintetiza, reflexiona y simboliza la información que ha obtenido, dándole un sentido que posteriormente se modifica en cantidad y calidad al darlo a conocer a otras personas. A este proceso abstracto subyacen actos tan antiguos como la tradición oral, mencionada anteriormente. El acto de contar -en este caso, lo que se lee- transforma el significado del texto y al lector mismo, pues bien se sabe que una vez que ha leído algo, el ser humano no vuelve a ser el mismo, aunque sea en una mínima proporción.

En palabras de Garrido (2004): "Sabemos que alguien comprende un texto cuando es capaz de traducirlo a sus propias palabras, comentarlo oralmente y por escrito, resumirlo, convertirlo en imágenes, corregirlo, tener una opinión sobre su contenido, compararlo con otros textos" (p. I56). Hasta este punto, el lector desarrolla su capacidad de aprender de lo que lee, pero también va implícita en este acto la comunicación que establece consigo al construir opiniones y hacerse una idea propia del texto, es decir, al simbolizarlo. "Una persona aprende a leer cuando aprende a comprender el texto, así como aprende a hablar cuando aprende a dar sentido y significado a lo que escucha decir y aprende a usarlo él mismo para expresarse y comunicarse" (Garrido, 2004, p. I69). Puede decirse que la base de la comprensión lectora es la construcción individual de significado, misma que aprovecha los conocimientos previos adquiridos gracias a la comunicación, un proceso que dota de sentido al mundo que conocemos y, de forma circular, necesita ser simbolizado individualmente para poder existir. 


\section{Contexto, problema de intervención y objetivos}

Los jóvenes estudiantes de secundaria en Coscomatepec presentan dificultades para la comprensión lectora, el análisis, la reflexión y la consecuente producción escrita, a pesar de que durante la educación primaria y en el nivel actual fueron parte de actividades propuestas por programas de lectura institucionales, tales como tutorías, evaluaciones de la ruta de mejora y diversos encuentros de poesía, dramaturgia e incluso ortografía, entre otros.

Por tales razones, se trabajó con estudiantes de tercer grado de la Escuela Secundaria Técnica No. 39. Son originarios prácticamente en su totalidad del municipio de Coscomatepec de Bravo y comunidades aledañas, en el centro de Veracruz. Esta zona está catalogada como semi-rural, pues las actividades económicas principales son la agricultura, la ganadería y el comercio informal, en las que los jóvenes se involucran colaborando con su familia. Esta localidad constituye la cabecera de un municipio con alrededor de 57 ooo habitantes. Entre otras alternativas para cursar la educación básica aquí, se ofrece a la población adolescente dos telesecundarias y una escuela secundaria privada.

Se destinó a los alumnos de la Secundaria Técnica debido a que es la escuela con mayor población de alumnos en el municipio. Alberga a más de 800 estudiantes distribuidos en I8 grupos. No cuenta con biblioteca, sólo con un acervo de libros de texto y algunas obras literarias obtenidas mediante donaciones, las que no ascienden a más de I5o ejemplares y no están clasificadas ni actualizadas. Estos volúmenes se ubican en estanterías dentro del "aula de medios", donde los alumnos toman algunas clases de computación o acceden a material dispuesto en internet.

En este municipio esporádicamente han surgido iniciativas o posibilidades de invitación a la lectura, tales como algunas presentaciones de libros, concretadas en el marco de la fiesta cívica que se realiza año con año durante la primera semana de octubre, pero definitivamente no hay continuidad en las actividades culturales. Este panorama se completa con el hecho de que en Coscomatepec no existe una sola librería, salvo dos tiendas de artículos religiosos que incluyen la venta de libros. Las librerías más cercanas se encuentran en la ciudad de Córdoba, a una hora de camino.

El grupo concreto de adolescentes de secundaria estuvo constituido por jóvenes que han establecido una distancia con la lectura por carecer de estímulos en el entorno para acercarse a ésta. Si a esto se suma la inexistencia de biblioteca en la institución educativa, y la falta de recursos en el hogar para acceder a libros, el panorama se convierte en un área de oportunidad para promover la lectura, específicamente de textos relativos a experiencias e intereses propios de niños y jóvenes.

El objetivo general de este proyecto de intervención ha sido el de contribuir al fortalecimiento del hábito lector entre adolescentes de tercer grado de la Escuela Secundaria Técnica No 39 de Coscomatepec, a partir de la creación de un círculo de lectura que los conduzca a la producción de contenidos multimedia, entre otras actividades que les permitan, mediante un plan pertinente y constante, valorar y difundir la lectura como 
fuente de conocimiento y evolución personal. También se planteó 5 objetivos particulares: (I) Analizar los hábitos lectores de los adolescentes coscomatepecanos, para determinar los factores que les afectan durante el desarrollo de su capacidad lectora, tanto en el ambiente escolar como en el familiar y comunitario; (2) Motivar a los jóvenes para que construyan un hábito de lectura, a pesar de los obstáculos económicos, académicos o emocionales que hayan provocado su distanciamiento de la lectura en general; (3) Impulsar entre estos adolescentes la construcción de ideas a partir de los textos abordados, para que desarrollen la capacidad de expresarlas de manera escrita o audiovisual; (4) Demostrar que los adolescentes pueden convertirse en difusores de lectura mediante la sensibilización y el intercambio de ideas con otros lectores; y (5) Utilizar la promoción de la lectura entre estos jóvenes como un punto de interacción entre ellos, sus padres, profesores y miembros de la comunidad directamente involucrados en su educación básica. Se pretendió probar que el trabajo en círculo de lectura, encaminado a la producción y publicación de contenido multimedia, demostrará que los adolescentes de Coscomatepec pueden convertirse en lectores y creadores potenciales así como difusores efectivos de la práctica lectora.

\section{Metodología}

El proyecto inició a partir de la primera semana de mayo de 20I5, con la sesión del círculo de lectura denominado "Lectores en círculo". Previamente, durante las dos últimas semanas de abril, se realizó el contacto con las autoridades de la Escuela Secundaria Técnica No. 39 a fin de que conocieran las características de la propuesta y brindaran la oportunidad de realizar la difusión entre los estudiantes, específicamente los 6 grupos que conformaban en ese momento el tercer grado, puesto que eran quienes cumplían con la edad adecuada para las lecturas y actividades proyectadas. Se preveía que a partir de la difusión del círculo se conformara un grupo de 15 a 20 adolescentes.

Se propuso realizar i2 sesiones de círculo de lectura, una por semana, los jueves por la tarde, con duración de una hora y media, desde el o7 de mayo hasta el 23 de julio del año en curso. A partir de la primera sesión se creó un grupo público en Facebook, administrado por la promotora, a fin de que se compartiera material referente a la lectura en red, así como propuestas, avisos y aclaraciones. El blog comenzó a funcionar a partir de la séptima sesión del círculo de lectura, con los productos de las primeras seis sesiones, previa autorización de los jóvenes autores. Al término de las sesiones, durante el mes de septiembre, se organizó con los integrantes del círculo un encuentro de lectura con temática adolescente, en un pequeño salón social particular. En este encuentro los integrantes del círculo presentaron los productos publicados en la página web, además de recomendaciones de lectura a sus compañeros, padres de familia, docentes y miembros de la comunidad. 
Para conocer mejor al público lector sobre el que se enfocaría la propuesta de intervención, se diseñó una encuesta de carácter anónimo que fue aplicada a 50 alumnos que cursaban en ese momento el tercer grado de educación secundaria en la Escuela Secundaria Técnica No. 39 de Coscomatepec. Los jóvenes que habrían de responderla fueron elegidos al azar, de una población de i 98 alumnos distribuidos en 4 grupos, a saber, $3^{\circ}$. C, D, E y F. Había dos grupos más, $3^{\circ}$. A y B, a cuyos integrantes no se aplicó la encuesta por falta de disponibilidad de tiempo.

La función diagnóstica de este proyecto consistió en conocer las preferencias y hábitos lectores de los adolescentes a través de un cuestionario. También se realizó una retroalimentación a manera de cierre de cada sesión del círculo de lectura, para obtener impresiones, opiniones y encaminar la reflexión posterior que permitiera a los jóvenes crear durante la semana un producto de formato libre con base en la lectura. Dicho producto consistió en un texto, una fotografía, un video o un audio que se compartió en la página web a partir de la quinta sesión de círculo.

Para interpretar los resultados de la aplicación, se contó con la colaboración de estudiantes del séptimo semestre de la Facultad de Estadística e Informática de la Universidad Veracruzana, quienes también elaboraron los gráficos que acompañan este análisis. Dicha encuesta constó de 24 preguntas de opción múltiple.

Los textos abordados en este proyecto fueron seleccionados con base en el tema propuesto para cada sesión. Se tomó en cuenta la brevedad y coincidencia con intereses comunes a los adolescentes, los cuales fueron revelados por la encuesta diagnóstica antes mencionada. Se estructuró un programa de lecturas y actividades integrado como anexo al reporte de esta intervención. A continuación se muestra un esquema general de dicho

Tabla 1. Panorama general del plan de lecturas y actividades propuestas para las sesiones de círculo de lectura con adolescentes (página siguiente) 


\begin{tabular}{|c|c|c|c|}
\hline Sesión & Tema & Texto seleccionado & Actividades \\
\hline 1 & $\begin{array}{l}\text { Historias de } \\
\text { espantos }\end{array}$ & "Dicen" de Felipe Garrido, cuento & $\begin{array}{l}\text { Lectura en voz alta y narración } \\
\text { oral de historias locales de terror. }\end{array}$ \\
\hline 2 & Mascotas & $\begin{array}{l}\text { "El gato" (Le chat), de Charles Bau- } \\
\text { delaire, poema en versión bilingüe. } \\
\text { "Patio de tarde", de Julio Cortázar, } \\
\text { cuento }\end{array}$ & $\begin{array}{l}\text { Leer en voz alta en ambos idio- } \\
\text { mas. } \\
\text { Escribir un texto dedicado a una } \\
\text { mascota. }\end{array}$ \\
\hline 3 & La imaginación & $\begin{array}{l}\text { "La luz es como el agua", de Gabriel } \\
\text { García Márquez, cuento }\end{array}$ & $\begin{array}{l}\text { Leer en silencio e identificar } \\
\text { las preferencias de ambiente de } \\
\text { lectura. }\end{array}$ \\
\hline 4 & Nuestro universo & $\begin{array}{l}\text { "Si sobrevives...”, de Jaime Sabines, } \\
\text { poema. }\end{array}$ & $\begin{array}{l}\text { Relacionar el poema con el con- } \\
\text { cepto de universalidad a través de } \\
\text { un mandala. }\end{array}$ \\
\hline 5 & Secretos & $\begin{array}{l}\text { "El melómano", de Eusebio Ruvalca- } \\
\text { ba, cuento. } \\
\text { "Sueño \#69", de Ana María Shua, } \\
\text { cuento. } \\
\text { "El parque”, de Felipe Garrido, cuen- } \\
\text { to. } \\
\text { "El drama del desencantado", de Ga- } \\
\text { briel García Márquez, cuento. }\end{array}$ & $\begin{array}{l}\text { Seleccionar uno de los textos } \\
\text { leídos y escribir una continuación } \\
\text { breve desentrañando las motiva- } \\
\text { ciones de los personajes. }\end{array}$ \\
\hline 6 & Sueños & $\begin{array}{l}\text { Poemas tomados de la antología poé- } \\
\text { tica El placer de soñar, de Francisco } \\
\text { Hernández. }\end{array}$ & $\begin{array}{l}\text { Hacer una fotografía ilustrativa } \\
\text { del poema. }\end{array}$ \\
\hline 7 & El futuro I & $\begin{array}{l}\text {-Lección " } 25 \text { ", capítulo del libro Dios } \\
\text { nunca parpadea de Regina Brett. }\end{array}$ & $\begin{array}{l}\text { Escribir una lista de deseos por } \\
\text { cumplir. }\end{array}$ \\
\hline 8 & El futuro II & $\begin{array}{l}\text {-"Desiderata" de Max Ehrmann, } \\
\text { poema. }\end{array}$ & $\begin{array}{l}\text { Recrear la lista de deseos en una } \\
\text { producción audiovisual. }\end{array}$ \\
\hline 9 & La música & $\begin{array}{l}\text { "El campamento" de Luis Pescetti, } \\
\text { canción } \\
\text { "La música" de Eduardo Galeano, } \\
\text { cuento }\end{array}$ & $\begin{array}{l}\text { Identificar gustos musicales y su } \\
\text { relación con otros textos litera- } \\
\text { rios. }\end{array}$ \\
\hline 10 & Los viajes I & -Cortometraje "Leer te transporta" & $\begin{array}{l}\text { Identificar títulos y personajes } \\
\text { literarios del cortometraje. }\end{array}$ \\
\hline 11 & Los viajes II & $\begin{array}{l}\text {-Relatos breves de El libro de la ima- } \\
\text { ginación, de Edmundo Valadés }\end{array}$ & $\begin{array}{l}\text { Seleccionar un relato y escribir la } \\
\text { continuación del viaje. }\end{array}$ \\
\hline 12 & La lectura & $\begin{array}{l}\text { "La función del lector 1" de Eduardo } \\
\text { Galeano, texto con audio de Margari- } \\
\text { ta Castillo, Radio UNAM. } \\
\text { Cortometraje: "The fantastic flying } \\
\text { books of Mr. Morris Lessmore". }\end{array}$ & $\begin{array}{l}\text { Escribir un párrafo de reflexión } \\
\text { sobre la importancia de la lectura } \\
\text { en la vida. }\end{array}$ \\
\hline
\end{tabular}


plan:

Cabe señalar que en este plan también se incluyó la descripción del inicio, desarrollo y cierre de cada sesión, momentos en los cuales se integró el intercambio de ideas sobre libros leídos durante la semana, seleccionados libremente por cada participante, así como el abordaje en plenaria de cada tema, los espacios para el análisis de los textos programados y las conclusiones. En cada sesión se puso en práctica diferentes estrategias de animación a la lectura, cuyo impacto y pertinencia se estudia en la especialización, por ejemplo, lectura en voz alta, lectura en silencio, lectura coral, dinámicas de integración mediante de juegos de palabras y narración oral.

\section{Implementación de la estrategia de intervención}

A principios de abril de 20I5, se solicitó a las autoridades de la Escuela Secundaria Técnica No. 39, de Coscomatepec, la oportunidad de promover el círculo de lectura entre los grupos de tercer grado, mediante carteles colocados en áreas comunes y visitas al aula para invitar formalmente.

El espacio físico para las reuniones del círculo fue una sala especialmente ambientada, con ventilación, luz natural y artificial, sillas, almohadas, mesas, repisas y pizarrón. La estrategia de promoción implica que los jóvenes asocien la lectura a un ambiente distinto de la escuela tradicional. El acervo bibliográfico que estuvo al alcance de los jóvenes durante las sesiones en esta sala es propiedad particular. Se requirió también el uso de un proyector, material audiovisual e impreso, cuestionarios, entre otros.

En estas condiciones, se realizó la primera sesión de "Lectores en círculo” el jueves o7 de mayo, a las 5 de la tarde. Asistieron sólo 7 jóvenes, quienes sentaron el precedente para la futura difusión del grupo y continuaron regularmente hasta el final de la intervención.

A lo largo de las i2 sesiones, la asistencia fluctuó entre 6 y I 5 jóvenes, un número relativamente bajo en comparación con el público invitado, pero suficiente para la aplicación del proyecto. La dinámica de cada sesión se dividía en 4 momentos:

I. Al inicio de la sesión, cada uno compartía oralmente el avance de lectura de la semana. Abordaban un libro que hubieran conseguido por sus propios medios, o que hubieran elegido de mi acervo disponible. En un lapso no mayor a 5 minutos, cada quien explicaba cómo se iba desarrollando su lectura. Si se trataba de una novela o un libro de cuentos, hablaban sobre los personajes, la trama y sus impresiones; si estaban leyendo poemas, citaban frases que les hubieran gustado, o si se trataba de algún libro de historia, divulgación científica o arte, explicaban los temas principales así como su opinión al respecto.

2. El segundo momento de la sesión de "Lectores en círculo" consistía en hacer una lectura breve. Se hizo una selección de textos cortos -poemas o cuentos- con base en un tema para cada sesión. La estrategia varió entre la lectura en voz alta, la lectura 
comentada, la lectura grupal y la lectura en silencio. Entre los temas abordados a través de los textos se encuentran las mascotas, el futuro, lo desconocido, la música, los viajes y el futuro.

3. Una vez hecha la lectura correspondiente, se realizaba una actividad relacionada con el tema. Algunas veces se estableció un vínculo de lo leído con material audiovisual (canciones, videos, cortometrajes y documentales); otras, los asistentes escribieron o dibujaron sus ideas de la sesión, lo cual proveyó de material que después hubo de publicarse en el blog.

4. La sesión finalizaba con una recapitulación del tema abordado. Era éste el momento en el que los jóvenes compartían en plenaria las ideas y puntos de vista que habían obtenido de la sesión.

Durante la segunda sesión, se creó un grupo de WhatsApp para mantenerse en comunicación por cualquier eventualidad. Sin embargo, no todos los jóvenes contaban con un dispositivo móvil con acceso a esta aplicación. Entonces se creó en Facebook el grupo denominado "Lectores en círculo". Está configurado como un grupo "abierto", es decir, el público en general puede acceder a los contenidos que se comparten y también se puede solicitar la aprobación para integrarse.

La evolución del grupo de Facebook a lo largo de las i2 sesiones y hasta la fecha es muy interesante. Inició con 8 miembros y actualmente cuenta con 224. Algunos fueron incorporados por los mismos integrantes del círculo de lectura, otros solicitaron ingresar al grupo por voluntad propia. Los integrantes también han publicado avisos, videos sobre historias, audios de libros y textos de interés provenientes de sitios como Youtube, blogs y páginas diversas.

La otra plataforma virtual del grupo fue el blog "Lectores en círculo", creado desde el mes de junio, alrededor de la séptima sesión, bajo el dominio www.lectoresencirculo. blogspot.com. En este espacio se consignaron textos de los lectores, fotografías que ellos tomaron inspirados por alguna lectura y presentaciones convertidas en video, donde ellos expresan su personalidad a partir de una de las sesiones. Los jóvenes envían sus colaboraciones por correo electrónico y una vez hecha la publicación, se vincula al grupo de Facebook para que los miembros entren a ver las publicaciones recientes.

La meta la intervención era conseguir que los jóvenes demostraran una transformación en sus hábitos lectores e interactuaran, más allá del círculo y del espacio virtual, con miembros de su entorno. Esta acción permitiría demostrar que cuando los jóvenes se interesan genuinamente en una actividad, son capaces de difundirla con efectividad.

Para organizar el Primer Encuentro de Adolescentes Lectores en Coscomatepec, fue necesario emprender una campaña de difusión en la que los integrantes de "Lectores en círculo" participaran activamente. Alrededor de la octava sesión, se dotó al círculo de una imagen que le otorgara identidad. Con el apoyo de una diseñadora gráfica, surgió el logotipo de "Lectores en círculo", cuyos colores y elementos corresponden a las características del espacio donde se realizaron las sesiones.

Los carteles diseñados se colocaron en lugares públicos y en la Escuela Secundaria 
Técnica No. 39. Se creó el evento desde el grupo de Facebook. Fueron necesarias dos reuniones para organizar la participación de los jóvenes lectores, quienes además apoyaron en detalles de logística, tales como sonido, mobiliario, ambigú y la disposición de una mesa de recomendaciones de lectura para que el público conociera los libros que ellos leyeron a lo largo de las sesiones, acompañados por pequeños comentarios de recomendación hechos a mano.

El evento se realizó el viernes 23 de septiembre de 20I5, en punto de las 5 de la tarde, en las instalaciones de un pequeño salón de eventos de Coscomatepec. Las condiciones de clima fueron adversas, pues llovió considerablemente, A pesar de esto, asistieron alrededor de 40 personas, entre padres de familia, docentes, amigos de los lectores y jóvenes estudiantes.

Luego de una presentación breve, los adolescentes, organizados en grupos de 4, pasaron al frente libro en mano para comentar al público las razones por las que recomendaban el texto que eligieron, sus impresiones y también cómo ha sido hasta el momento su experiencia lectora; todo esto en un lapso de 5 minutos por persona. Participaron I2 adolescentes en tres grupos. En el intermedio de cada grupo, se proyectó videos sobre la lectura, se dio a conocer al público el blog y yo misma realicé una lectura en voz alta.

\section{Resultados y discusión}

En una sesión posterior al evento, los jóvenes del círculo de lectura expresaron su satisfacción por haber participado en este hecho novedoso. En realidad, puede decirse que el encuentro cohesionó al grupo, pues todos pidieron que las sesiones continuaran, llegaron nuevos integrantes y el grupo de Facebook registró numerosas solicitudes de nuevos miembros. Hasta la fecha, "Lectores en círculo" sigue reuniéndose los jueves por la tarde, con una asistencia variable de adolescentes que ya finalizaron la escuela secundaria y ahora, en el bachillerato, consideran el círculo de lectura como una actividad extraescolar importante.

Especial atención merecen los testimonios de los jóvenes que participaron en el encuentro de adolescentes, ya que aprovecharon la oportunidad de estar ante el micrófono para expresar de viva voz lo que ha significado para ellos el compartir gustos e intereses por la vía de los libros.

Otro resultado importante fue la evolución de esta propuesta, gracias a la adecuación del espacio y el diseño de una imagen de identidad. Prácticamente, el círculo se convirtió en la razón para fundar una sala de lectura, algo hasta este momento inexistente en Coscomatepec, y que en el futuro puede mejorar y habilitarse para otro tipo de público lector, con nuevas actividades y propuestas. La realización de este proyecto de intervención ha sentado aquí un precedente para la gestión cultural en lo que respecta a la promoción de la lectura. No se descarta la posibilidad de registrar el seguimiento e implementar mejoras estratégicas con base en nuevos recursos, por ejemplo, mobiliario adecuado y donaciones 
de libros.

El propósito de esta intervención ha sido favorecer el hábito lector de los adolescentes de entre I3 y i6 años, estudiantes del tercer grado en la Escuela Secundaria Técnica No. 39 en Coscomatepec, Veracruz. A partir del reconocimiento de las características de sus propias prácticas y experiencias lectoras, los jóvenes se integraron a un círculo de lectura, el cual funcionó en sesiones donde se combinaron textos previamente seleccionados con actividades lúdicas. Mediante la lectura en voz alta, en silencio, la discusión grupal entre otras estrategias, hicieron análisis y reflexión de lo leído, demostraron su capacidad para establecer relaciones entre el texto y la realidad que los circunda, a través de un escrito de cualquier género; un producto visual, tal como una fotografía o un video, o bien a través de un audio. Estos productos se publicaron en un blog específicamente diseñado para ello.

Contribuyeron a la difusión de la lectura en Coscomatepec, organizando y protagonizando un encuentro de lectura con temática adolescente, donde dieron a conocer su producción multimedia y recomendaron sus propias lecturas, interactuando así con miembros de su entorno, por ejemplo sus compañeros, padres y profesores.

Con tales bases, este grupo de adolescentes coscomatepecanos se sintió motivado a persistir en el hábito lector. Los chicos se interesaron por conocer diversos autores y géneros, establecieron contacto con la sociedad a través de este acto particular, demostraron su capacidad creativa, utilizaron los recursos tecnológicos, y no menos importante, registraron un avance en la producción escrita gracias a la práctica cotidiana. Los resultados obtenidos son acordes con el planteamiento teórico de que la construcción del propio conocimiento se combina eficientemente con la interacción, puesto que también a través de la red social y el blog, los jóvenes dieron a conocer ideas, comentarios y creaciones propias, revelaron aspectos de su personalidad y descubrieron nuevas maneras de expresarse.

Sin duda la experiencia con este grupo piloto servirá para implementar proyectos de promoción de la lectura en Coscomatepec. Será necesario tener en cuenta que la tecnología sigue innovando y habrá que indagar entre los recursos de lectura y escritura que nos ofrece. De igual manera, será fundamental persistir en la difusión cultural, mantener vigente la actividad del círculo e impulsar la mejora de una sala de lectura, hasta constituirla como un espacio de calidad para los lectores coscomatepecanos. 


\section{Conclusiones}

A lo largo del año 20I5, este proyecto de intervención para promover la lectura fue tomando sentido gracias al desarrollo gradual de ideas enriquecidas con las experiencias educativas de la Especialización en Promoción de la Lectura. Fue necesario abrevar en nuevas fuentes de conocimiento, en discusiones actuales sobre campos como las cartografías lectoras, los géneros literarios, las estrategias e incluso ámbitos diferentes a los planteados por nosotros mismos, para darnos cuenta de que la intención de "contagiar" a otros el gusto por la lectura requiere también un trabajo arduo, bien planeado, y un esfuerzo particular para luchar contra los pronósticos poco favorables al desarrollo de actividades culturales en medio de la crisis de violencia, inseguridad y pobreza que se experimenta en México.

Este proyecto en particular tuvo la ventaja de haber sido desarrollado en un lugar de matices diversos, donde todavía existe rezago económico y educativo, pero los jóvenes ya interactúan con las nuevas tecnologías, un lugar fértil donde queda mucho trabajo por hacer en la formación de nuevos lectores.

Con base en las evidencias, se puede concluir que la intervención con adolescentes fue provechosa, aunque hay todavía diversas áreas de oportunidad para profundizar en el conocimiento de las condiciones y las vías que nos conducen a elevar la calidad de la lectura. A pesar del trabajo de difusión del círculo y la invitación permanente a participar, el grupo que se mantuvo bien cohesionado hasta el final fue reducido, contrastante con la respuesta al grupo análogo en redes sociales. Esto evidencia que los jóvenes sienten curiosidad hacia propuestas culturales como ésta, pero muestran muy poca disposición para participar activamente en ellas.

Finalmente, la esencia del fomento a la lectura es compartir lo poco o mucho que a lo largo de la vida se ha aprendido, dar a conocer a los demás la condición que nos humaniza, la de pensar y optar por lo mejor para los otros y para nosotros mismos. La promoción de la lectura demuestra con este tipo de proyectos la determinada intención de crear lectores pensantes. Esto no garantizará que sean mejores personas, pero sí contribuirá a forjarlos como seres humanos capaces de tomar mejores decisiones. Tan sencilla como parece, esta idea debe filtrarse entre los jóvenes para que estén conscientes de todo lo que pueden lograr leyendo. Es un compromiso de los lectores consolidados poner en las manos de los más jóvenes la lectura, el alimento del genio creativo que llevan dentro. 


\section{Referencias bibliográficas}

- Bahloul, J. (2002). Lecturas precarias. México: FCE.

- Cassany, D. (2006). Tras las líneas: Sobre la lectura contemporánea. Barcelona: Anagrama.

- Castronovo, A. (2004). Promoción de la lectura: desde la librería hasta los nuevos lectores. Buenos Aires: Colihue.

- Chambers, A. (2007). El ambiente de la lectura. México: FCE.

- Chance, R. y Lesesne T. (2OI2). Rethinking reading promotion. Teacher Librarian, pp- 2629. Recuperado en www.teacherlibrarian.com

- Colomer, T. (2005). Andar entre libros. La lectura literaria en la escuela. México: FCE.

- CONACULTA (2015). Encuesta Nacional de Lectura y Escritura 2015-2018. Recuperado en www.observatorio.librosmexico.mx

- Garrido, F. (2004). Para leerte mejor. México: Paidós.

- Garrido, F. (2OI2). Manual del buen promotor. México: CONACULTA.

- Gómez, C. y Coll, S. (i994). De qué hablamos cuando hablamos de constructivismo. Cuadernos de pedagogía. Recuperado en https://scholar.google.es

- Gómez Martínez, P. (20I4). Documental En la luna. Recuperado en http://www.enlaluna. org

- Lerner, D. (2008). Leer en la escuela: lo real, lo posible y lo necesario. México: FCE.

- Manguel, Alberto. (20II). Una historia de la lectura. México: Almadía.

- Martos, E., Campos F.-Fígares, M., Cordón, J.A. y Gómez Díaz, R. (2OI4). Diccionario Digital de Nuevas Formas de Lectura y Escritura. Universidad de Salamanca y Red Internacional de Universidades Lectoras España. Recuperado en http://dinle.eusal.es

- Morales, Ó. Et al. (2005). Consideraciones pedagógicas para la promoción de la lectura dentro y fuera de la escuela. Revista de Teoría y Didáctica de las Ciencias Sociales. MéridaVenezuela, núm. IO, pp. 195-218. Recuperado en http://www.oei.es 
- Petit, M. (2013). Nuevos acercamientos a los jóvenes y la lectura. México: FCE.

- Pons, X. (2OIO). La aportación a la psicología social del interaccionismo simbólico: una revisión histórica. eduPsykhé. Vol. 9, No. I, pp. 23-4I.

- Ramos, A. (2015). Contra una promoción de la lectura. Letras libres. Recuperado en http://www.letraslibres.com/blogs/polifonia/contra-una-promocion-de-la-lectura

- Sarland, C. (2006). La lectura en losjóvenes. Cultura y respuestas. México: FCE.

- Storni, P. (2009). Los jóvenes y la lectura: la construcción de nuevas formas de sociabilidad desde las prácticas lectoras. en III Jornadas de Jóvenes Investigadores. Argentina: Universidad Nacional de Tucumán. Recuperado en http://scait.ct.unt.edu.ar/pubjornadas2oog/ pdf 